\title{
Luteolin protects mice from severe acute pancreatitis by exerting HO-1-mediated anti-inflammatory and antioxidant effects
}

\author{
JIE XIONG $^{1,2^{*}}$, KEZHOU WANG ${ }^{3 *}$, CHUNXIAO YUAN $^{4}$, RONG XING $^{5}$, JIANBO NI $^{1}$, \\ GUOYONG HU $^{1}$, FENGLING CHEN ${ }^{2}$ and XINGPENG WANG ${ }^{1}$
}

\author{
${ }^{1}$ Department of Gastroenterology, Shanghai General Hospital, Shanghai Jiao Tong University School of Medicine, \\ Shanghai 200080; ${ }^{2}$ Department of Endocrinology, Shanghai Ninth People's Hospital, Shanghai Jiao Tong University \\ School of Medicine, Shanghai 201999; ${ }^{3}$ Department of Biochemistry and Molecular Cell Biology, Shanghai \\ Jiao Tong University School of Medicine, Shanghai 200025; ${ }^{4}$ Department of Pathology and Pathophysiology, \\ Dalian Medical University; ${ }^{5}$ Department of Nephrology, The Second Hospital Affiliated \\ to Dalian Medical University, Dalian, Liaoning 116044, P.R. China
}

Received February 3, 2016; Accepted October 27, 2016

DOI: $10.3892 / \mathrm{ijmm} .2016 .2809$

\begin{abstract}
Reseda odorata L. has long been used in traditional Asian medicine for the treatment of diseases associated with oxidative injury and acute inflammation, such as endotoxemia, acute lung injury, acute myocardial infarction and hepatitis. Luteolin, the main component of Reseda odorata L., which is also widely found in many natural herbs and vegetables, has been shown to induce heme oxygenase-1 (HO-1) expression to exert anti-inflammatory and antioxidant effects. In this study, we aimed to examine the effects of luteolin on mice with severe acute pancreatitis (SAP), and to explore the underlying mechanisms. Cerulein and lipopolysaccharide were used to induce SAP in male Institute of Cancer Research (ICR) mice in the SAP group. The SAP group was divided into 4 subgroups, as follows: the vehicle, luteolin, zinc protoporphyrin (ZnPP) only, and luteolin (Lut) $+\mathrm{ZnPP}$ (luteolin plus zinc protoporphyrin treatment) groups. The wet/dry weight ratios, hematoxylin and eosin staining and pathological scores of pancreatic tissues were assessed and compared to those of the control mice. Amylase, lipase, nuclear factor- $\kappa \mathrm{B}(\mathrm{NF}-\kappa \mathrm{B})$ and myeloperoxidase activities, and malondialdehyde, tumor necrosis factor $\alpha(\mathrm{TNF} \alpha)$,
\end{abstract}

Correspondence to: Professor Xingpeng Wang, Department of Gastroenterology, Shanghai General Hospital, Shanghai Jiao Tong University School of Medicine, 100 Haining Road, Hongkou, Shanghai 200080, P.R. China

E-mail: wangxp1965@aliyun.com

Professor Fengling Chen, Department of Endocrinology, Shanghai Ninth People's Hospital, Shanghai Jiao Tong University School of Medicine, 280 Mohe Road, Baoshan, Shanghai 201999, P.R. China E-mail: chenf11993@126.com

${ }^{*}$ Contributed equally

Key words: luteolin, severe acute pancreatitis, heme oxygenase-1, interleukin-10, nuclear factor- $\kappa \mathrm{B}$ interleukin (IL)-6, IL-10 and HO-1 levels, as well as the expression of HO-1 were determined in serum and/or pancreatic tissue samples. SAP was successfully induced in male mice compared to normal control mice. The wet/dry weight ratios, pathological scores, and amylase and lipase activity, as well as the levels of TNF $\alpha$ and IL- 6 were significantly reduced in the pancreatic tissues of the mice in the Lut group compared with those of the mice in the vehicle group. The Lut group exhibited a significant increase in HO-1 expression in the pancreas and enhanced serum HO-1 and IL-10 levels compared with the vehicle group. The suppression of HO-1 activity in the ZnPP group significantly abolished the protective effects of luteolin. NF- $\kappa \mathrm{B}$ expression in the pancreatic tissues from the mice in the Lut + ZnPP group was significantly increased following the suppression of HO-1 activity. On the whole, our findings demonstrate that luteolin protects mice from SAP by inducing HO-1-mediated antiinflammatory and antioxidant activities, in association with the suppression of the activation of the NF- $\kappa \mathrm{B}$ pathway.

\section{Introduction}

Acute pancreatitis (AP) remains a common acute abdominal disease, which includes mild acute pancreatitis (MAP) and severe acute pancreatitis (SAP) (1). Patients with MAP can exhibit an improvement in severity or can even be cured by active treatment within 1 week. However, SAP rapidly ensues, readily causing systemic inflammatory response syndrome (SIRS) in the early stages and subsequently, multiple organ dysfunction syndrome (MODS), with a high fatality rate of up to $15-20 \%$. Despite multiple basic and clinical studies assessing SAP, no ideal therapeutic drug is yet available $(2,3)$.

Luteolin (Lut, 3, 4', 5', 7-tetrahydroxyflavone), a natural flavonoid first isolated from Reseda odorata $L$. and is widely found in many vegetables and herbal medicines, has long been used in traditional Asian medicine for the treatment of diseases associated with oxidative injury and acute inflammation, such as endotoxemia, acute lung injury, acute myocardial infarction and hepatitis (4-6). Luteolin displays specific anti-inflamma- 
tory effects at micromolar concentrations, partly explained by its antioxidant capacity, including the activation of antioxidant enzymes, the suppression of nuclear factor- $\kappa \mathrm{B}(\mathrm{NF}-\kappa \mathrm{B})$ pathway activation and the inhibition of pro-inflammatory substances (4). However, the role and underlying pharmacological mechanisms of luteolin in diseases are largely unknown.

Recently, it has been reported that luteolin is an effective heme oxygenase-1 (HO-1) inducer and that it exerts anti-inflammatory effects in macrophages in a dose-dependent manner, leading to the suppression of inducible nitric oxide synthase (iNOS)-derived nitric oxide (NO) production, suggesting the potential therapeutic effects of luteolin in inflammatory diseases (7). HO-1 is the rate-limiting enzyme in heme degradation; it catalyzes the oxidative degradation of heme to equimolar quantities of carbon monoxide (CO), iron and biliverdin (8). Of note, HO-1 overexpression can be applied in multiple clinical conditions, such as organ transplantation, acute kidney injury, hypertension and atherosclerosis (9-14). Importantly, HO-1 is known to exhibit cytoprotective, antiinflammatory, anti-proliferative, antioxidant and anti-apoptotic activities, making it a promising therapeutic target for the treatment of inflammatory diseases of the gastrointestinal system (15). Panhematin leads to the rapid induction and activation of pancreatic HO-1, and has potential for use in the treatment of human pancreatitis (16). In addition, hemin-like compounds or hemin-activated macrophages prevent AP via the upregulation of HO-1 (17). In agreement with these studies, stressful conditions, such as severe hypoxia, hyperpyrexia and endotoxemia observed in patients with SAP can be alleviated by the appropriate induction of HO-1 levels $(18,19)$. Furthermore, $\mathrm{HO}-1$ exerts protective effects against cardiomyocytic apoptosis and oxidative stress by inhibiting NF- $\mathrm{KB}$ activity $(18,20,21)$.

Oxidative stress and the activation of $N F-\kappa B$ have been suggested to play important roles in SAP (22-24). However, whether luteolin exerts its anti-inflammatory and antioxidant effects by inducing HO-1 expression in SAP remains unknown. Therefore, in this study, we aimed to assess the protective effects of luteolin in mice with SAP induced by cerulein plus lipopolysaccharide (LPS), and unveil the underlying mechanisms.

\section{Materials and methods}

Chemicals. Purified luteolin (>99\%, CAS: 491-70-3) was purchased from Shanghai Tauto Biotech Co., Ltd. (Shanghai, China) and its quality was analyzed by high-performance liquid chromatography (HPLC) (Fig. 1). Cerulein, LPS and zinc protoporphyrin (ZnPP) were obtained from Sigma-Aldrich (St. Louis, MO, USA). Luteolin was dissolved in $35 \%$ propanediol to the concentration of $20 \mathrm{mg} / \mathrm{ml}$. Cerulein and LPS were dissolved in $0.9 \% \mathrm{NaCl}$ to the concentration of $10 \mu \mathrm{g} / \mathrm{ml}$ and $1 \mathrm{mg} /$ $\mathrm{ml}$, respectively. The ZnPP solution was prepared as follows: first, $25 \mathrm{mg} \mathrm{ZnPP}$ were dissolved in $3.3 \mathrm{ml} \mathrm{NaOH}(0.2 \mathrm{M})$ in a dark room and $0.2 \mathrm{M} \mathrm{HCl}$ was added to adjust the $\mathrm{pH}$ to 7.0 . Finally, saline was added to $50 \mathrm{ml}(0.5 \mathrm{mg} / \mathrm{ml})$. The resulting solution was stored away from light.

Animal model of SAP. Male Institute of Cancer Research (ICR) mice (8 weeks old; weighing 20-23 g) were purchased from Shanghai SLAC Laboratory Animal Co., Ltd. (Shanghai, China). The animals were maintained on a 12 h-light/12 h-dark cycle at $22^{\circ} \mathrm{C}$, given water ad libitum, fed standard laboratory chow and allowed to acclimatize for a minimum of 1 week. All animal-related procedures were approved by the Institutional Animal Care and Use Committee of Shanghai Jiao Tong University (Shanghai, China). This study was also performed under the permission of Science and Technology Commission of Shanghai municipality with the permit no. SYXK 2013-0050.

To investigate the optimal dose of luteolin, we first evaluated its pharmacological toxicity and half lethal dose $\left(\mathrm{LD}_{50}\right)$, and the effect of luteolin on cerulein plus LPS-induced SAP in mice was determined at different doses, including 25,50 and $100 \mathrm{mg} / \mathrm{kg}$. To investigate the effects of luteolin treatment on SAP, 54 male ICR mice were divided into 3 groups ( $n=18$ per group) as follows: the normal control (NC) group (without SAP), the SAP control group (mice with SAP treated with the vehicle) and the luteolin (Lut) group (SAP mice treated with luteolin). The mice were fasted for $12 \mathrm{~h}$ with free access to drinking water prior to the induction of SAP. SAP was induced by an intraperitoneal injection of $50 \mu \mathrm{g} / \mathrm{kg}$ cerulein (Sigma-Aldrich) in $0.9 \% \mathrm{NaCl}$, as previously described $(25,26)$. After the final administration, the animals were intraperitoneally injected with LPS (Sigma-Aldrich) at $5 \mathrm{mg} / \mathrm{kg}$. The mice in the Lut group were intraperitoneally injected with luteolin (Sigma-Aldrich) at $100 \mathrm{mg} / \mathrm{kg}$ $2 \mathrm{~h}$ prior to the induction of SAP. The SAP control group mice were intraperitoneally injected with equal volumes of $35 \%$ propanediol as the Lut group. In the NC group, the mice were continuously administered the same volume of saline 7 times. After modeling, the mice were still fasted but were allowed free access to drinking. Each group was subdivided into 3 subgroups to obtain serum and pancreatic tissues at the time points of 1,3 and $6 \mathrm{~h}$ post-modeling ( $\mathrm{n}=6$ per group). Blood $(1 \mathrm{ml})$ was collected by retro-orbital bleeding at 1,3 and $6 \mathrm{~h}$ after modeling under anesthesia with phenobarbital sodium $(50 \mathrm{mg} / \mathrm{kg})$ intraperitoneally. Serum samples were obtained by centrifugation $(900 \mathrm{x} \mathrm{g}, 5 \mathrm{~min})$ and stored at $-20^{\circ} \mathrm{C}$ for ELISA, amylase and lipase detection. Pancreatic tissues were extracted at 1, 3 and $6 \mathrm{~h}$ after modeling under anesthesia with phenobarbital sodium $(50 \mathrm{mg} / \mathrm{kg}$ ) intraperitoneally, and the pancreas head and tail were fixed in $4 \%$ paraformaldehyde and embedded in paraffin for pathological analysis; the remaining tissue was stored in liquid nitrogen.

In order to assess the potential effects of luteolin on SAP via the induction of HO expression, another 40 ICR mice (weighing 20-23 g) were divided into 5 groups $(n=8$ per group) as follows: the NC group, SAP model with vehicle treatment (SAP control) group, SAP model with ZnPP (Sigma-Aldrich) only treatment (ZnPP) group, SAP model with luteolin treatment (Lut) group and SAP model with luteolin plus $\mathrm{ZnPP}$ treatment (Lut $+\mathrm{ZnPP}$ ) group. The SAP model was established as described above. Lut + ZnPP group mice were intraperitoneally injected with $\mathrm{ZnPP}$ and luteolin at 5 and $100 \mathrm{mg} / \mathrm{kg}, 2 \mathrm{~h}$ before SAP modeling. Lut group and ZnPP group mice were intraperitoneally injected with 100 or $5 \mathrm{mg} / \mathrm{kg} \mathrm{ZnPP} 2 \mathrm{~h}$ before SAP modeling, respectively. SAP control groups were only treated with the vehicle.

Analysis of pancreas wet/dry weight ratio. The pancreatic tissue was removed from liquid nitrogen and weighed to obtain the wet weight. Subsequently, the pancreatic tissue was dried 


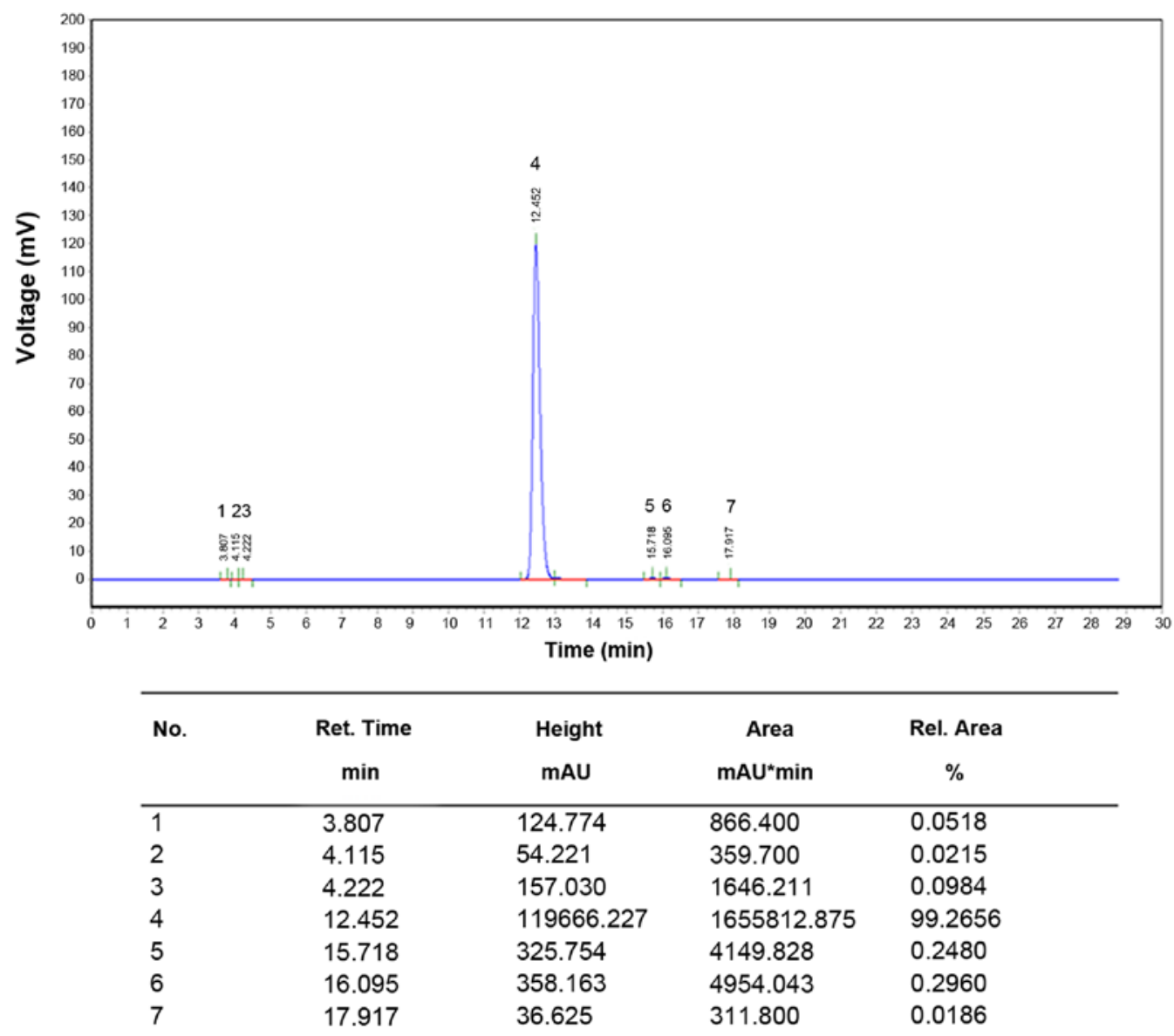

Figure 1. High-performance liquid chromatography (HPLC) pattern of luteolin (Lut).

at $60^{\circ} \mathrm{C}$ for $48 \mathrm{~h}$ and weighed to obtain the dry weight. Finally, the wet/dry weight ratios of the pancreas were calculated.

Analysis of biochemical indexes in serum and pancreas. The amylase and lipase activities were determined on an automatic biochemical analyzer Hitachi 7600-110 (Hitachi, Tokyo, Japan). Tumor necrosis factor $\alpha$ (TNF $\alpha$ ), interleukin (IL)-6, HO-1 and IL-10 levels in serum were assessed using ELISA kits (eBioscience, Inc., San Diego, CA, USA). Malondialdehyde (MDA), superoxide dismutase (SOD) and myeloperoxidase (MPO) levels in the pancreas were also evaluated using specific kits (Nanjing Jiancheng Bioengineering Institute, Nanjing, China) according to the manufacturer's instructions.

Detection of HO-1 activity and $\mathrm{CO}$ content in pancreatic tissue. HO-1 activity was assessed in pancreas samples as previously reported $(27,28)$. Briefly, tissue samples were homogenized in cool phosphate-buffered saline (PBS; $\mathrm{pH}$ 7.4) and centrifuged at $18,000 \mathrm{x}$ g for $15 \mathrm{~min}$ at $4^{\circ} \mathrm{C}$. The reaction system $(1 \mathrm{ml})$ was composed of tissue homogenate $(600 \mu \mathrm{l}), 0.8 \mathrm{mmol} / \mathrm{l}$ nicotinamide adenine dinucleotide phosphate (NADPH), $1 \mathrm{mmol} / \mathrm{l}$ glucose-6-phosphate, $0.2 \mathrm{U}$ glucose 6-phosphate dehydrogenase and $2.5 \mathrm{mmol} / \mathrm{l}$ protohemin. After thorough mixing, the reaction was incubated for $1 \mathrm{~h}$ at $37^{\circ} \mathrm{C}$ in a water bath with shaking in the dark; chloroform was added to terminate the reaction. The amounts of generated bilirubin were determined by absorbance at 464 and $530 \mathrm{~nm}$. HO-1 activity was expressed as the amount of bilirubin in $\mathrm{nmol} / \mathrm{h} / \mathrm{mg}$ protein. The $\mathrm{CO}$ content in the homog- enates was determined using a CO assay kit (Nanjing Jiancheng Bioengineering Institute) according to the manufacturer's instructions. The results were expressed as $\mu \mathrm{mol} \mathrm{CO} / \mathrm{g}$ tissue.

Histological analysis of pancreas tissue. The embedded pancreatic tissues were sectioned at $5 \mu \mathrm{m}$, and stained with hematoxylin and eosin (H\&E) for histological analysis, including the determination of pancreatic edema, inflammatory cell infiltration, bleeding and necrotic cell number. The double blind method was carried out by two pathologists at Shanghai No. 9 People's Hospital (Shanghai, China). Pancreatic tissue damage was evaluated as previously described by Rongione et al (29) and as shown in Table I: pathological score $=$ edema score + necrosis score + inflammatory cellular infiltration score + bleeding score. The higher the pathological score, the more severe the tissue damage. Five slices were assessed in each group.

Reverse transcription-quantitative PCR (RT-qPCR). RNA was extracted using TRIzol reagent (Invitrogen Life Technologies, Carlsbad, CA, USA). cDNA was obtained using a reverse transcription kit (Invitrogen Life Technologies), and qPCR performed using SYBR-Green (Takara Bio, Inc., Tokyo, Japan) on an ABI 7900 instrument (Applied Biosystems Foster City, CA, USA). The TNF $\alpha$, IL-6, IL-10 and HO-1 mRNA levels were detected and the relative mRNA levels were normalized to $\beta$-actin using the $\Delta \Delta \mathrm{Ct}$ method. The primers used are listed in Table II. 
Table I. Histological scoring for acute pancreatitis, as described by Rongione et al (25).

\begin{tabular}{|c|c|c|c|}
\hline Edema & Necrosis & $\begin{array}{l}\text { Inflammatory } \\
\text { cell infiltration }\end{array}$ & Bleeding \\
\hline $\begin{array}{l}1=\text { Focally increased } \\
\text { between lobules }\end{array}$ & $1=$ Periductal necrosis $(<5 \%)$ & $\begin{array}{l}1=\text { In ducts } \\
\text { (around ductal margins) }\end{array}$ & $\begin{array}{l}1=\text { In the parenchyma } \\
\text { bleeding }(0-25 \%)\end{array}$ \\
\hline $\begin{array}{l}2=\text { Diffusely increased } \\
\text { between lobules }\end{array}$ & $2=$ Focal necrosis $(5-20 \%)$ & $\begin{array}{l}2=\text { In the parenchyma } \\
\text { (in }<50 \% \text { of the lobules) }\end{array}$ & $\begin{array}{l}2=\text { In the parenchyma } \\
\text { bleeding }(25-50 \%)\end{array}$ \\
\hline $\begin{array}{l}3=\text { Acini disrupted } \\
\text { and separated }\end{array}$ & $\begin{array}{l}3=\text { Diffuse parenchymal } \\
\text { necrosis }(20-50 \%)\end{array}$ & $\begin{array}{l}3=\text { In the parenchyma } \\
\text { (in } 50-75 \% \text { of the lobules) }\end{array}$ & $\begin{array}{l}3=\text { In the parenchyma } \\
\text { bleeding }(50-75 \%)\end{array}$ \\
\hline $\begin{array}{l}4=\text { Obvious lobules } \\
\text { separated }\end{array}$ & $\begin{array}{l}4=\text { Diffuse parenchymal } \\
\text { necrosis }>50 \%\end{array}$ & $\begin{array}{l}4=\text { In the parenchyma } \\
(>75 \% \text { of the lobules) }\end{array}$ & $\begin{array}{l}4=\text { In the parenchyma } \\
\text { bleeding }>75\end{array}$ \\
\hline
\end{tabular}

Table II. Primers used in this study.

\begin{tabular}{ll}
\hline Genes & \multicolumn{1}{c}{ Primers } \\
\hline$T N F \alpha$ & F: 5'-TCTCTTCAAGGGACAAGGCTG-3' \\
& R: 5'-ATA GCAAATCGGCTGACGGT-3' \\
IL-6 & F: 5'-CTGGTCTTCTGGAGTTCCGTTTC-3' \\
& R: 5'-CATAGCACACTAGGTTTGCCGAG-3' \\
HO-1 & F: 5'-GATAGAGCGCAACAAGCAGAA-3' \\
& R: 5'-CAGTGAGGCCCATACC AGAAG-3' \\
IL-10 & F: 5'-CTTACTGACTGGCATGA GGATCA-3' \\
& R: 5'-GCAGCTCTAGGAGCATGTGG-3' \\
& F: 5'-GTCC CTCACCCTCCCAAAAG-3' \\
& R: 5'-GCTCCCTCAAC-ACCTCAACCC-3'
\end{tabular}

F, forward; R, reverse; TNF $\alpha$, tumor necrosis factor $\alpha$; IL-6, interleukin-6; HO-1, heme oxygenase-1.

Western blot analysis. The pancreatic tissue $(50 \mathrm{mg})$ was pulverized after being snap-frozen in liquid nitrogen. RIPA lysis buffer (Beyotime Institute of Biotechnology, Suzhou, China) was then added for total protein extraction. Pancreatic nucleoproteins were obtained using a specific kit (Nanjing KeyGen Biotech., Co., Ltd., Nanjing, China). Total protein concentrations were quantified using the BCA kit (Nanjing KeyGen Biotech., Co., Ltd.). Primary antibodies against HO-1 (sc-1796),

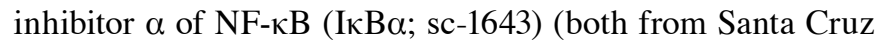
Biotechnology,Inc.,SantaCruz,CA,USA),NF-кB p65 (ab16502; Abcam, Cambridge, MA, USA), $\beta$-actin (sc-47778) and lamin B (sc-6216) (both from Santa Cruz Biotechnology, Inc.) were used. Donkey anti-goat IgG (Code no. 705-625-147), donkey anti-mouse IgG (Code no. 715-625-150) and donkey anti-rabbit IgG (Code no. 711-625-152) secondary antibodies were from Jackson Laboratory (Bar Harbor, ME, USA). Images were acquired on an Odyssey infrared fluorescent scanning imaging system (LI-COR Biosciences, Inc., Lincoln, NE, USA). Grey values of bands were quantitatively analyzed using Quantity One software, and relative protein levels expressed as the target band value/internal reference band value.

Immunohistochemical staining. Immunohistochemistry was employed to assess NF- $\mathrm{kB}$ expression in the pancreatic tissue specimens as previously described (30). The paraffin -embedded tissue sections were deparaffinized and incubated with $3 \%$ hydrogen peroxide for 10 min to block endogenous peroxidase. Antigen retrieval was then carried out with citrate buffer (0.01 M, pH 6.0) followed by blocking in goat serum. Following incubation for $15 \mathrm{~min}$ at room temperature, antiNF- $\mathrm{B}$ p65 (ab16502; 250x dilution) antibodies were added followed by overnightincubation at $4^{\circ} \mathrm{C}$. The following day, biotinlabeled goat anti-rabbit IgG was added followed by incubation at $37^{\circ} \mathrm{C}$ for $15 \mathrm{~min}$. The slides were then incubated at $37^{\circ} \mathrm{C}$ for $15 \mathrm{~min}$ in the presence of peroxidase-conjugated streptavidin. The sections were stained with 3,3'-diaminobenzidine (DAB) and counterstained with hematoxylin. Color separation was carried out with $1 \%$ hydrochloride and alcohol, followed by a 20-min wash. Five high power fields (x400 magnification) were randomly selected in each sample for analysis. Positive $\mathrm{NF}-\mathrm{kB}$ signals appeared brown. The positive rate was expressed as number of positive cells/number of total cells using the Image-Pro Plus software version 6.0 (Media Cybernetics, Rockville, MD, USA).

Statistical analyses. Data are presented as the means \pm standard error of the mean (SEM) and analyzed using the Statistical Package for the Social Sciences (SPSS) 18.0 software (SPSS, Inc., Chicago, IL, USA). An appropriate statistical test, either the Student's t-test or one-way analysis of variance (ANOVA) with post-hoc Tukey's test, was used to assess differences between groups. A value of $\mathrm{P}<0.05$ was considered to indicate a statistically significant difference.

\section{Results}

Luteolin markedly improves inflammatory cell infiltration and necrosis in the pancreas. In order to assess the effects of luteolin on SAP and determine an optimal dose with no observed adverse effect (NOAE) in mice, we first evaluated its pharmacological toxicity and $\mathrm{LD}_{50}$ value, which was $460 \mathrm{mg} / \mathrm{kg}$ (data not shown). Subsequently, routine biochemical parameters of the liver and kidneys were assessed following treatment with luteolin. No obvious liver or kidney toxicity was observed in the mice treated with luteolin at $100 \mathrm{mg} / \mathrm{kg}$. However, treatment with $200 \mathrm{mg} /$ $\mathrm{kg}$ of luteolin induced toxicity in mice. We also observed that luteolin protected the mice from cerulein plus LPS-induced SAP in a dose-dependent manner $(25,50$ and $100 \mathrm{mg} / \mathrm{kg})$ (data 
A

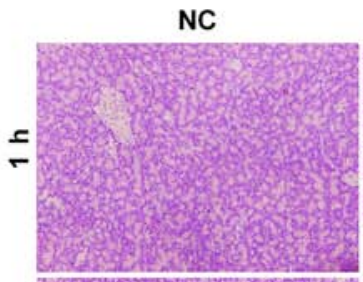

SAP+Vehicle

SAP+Lut
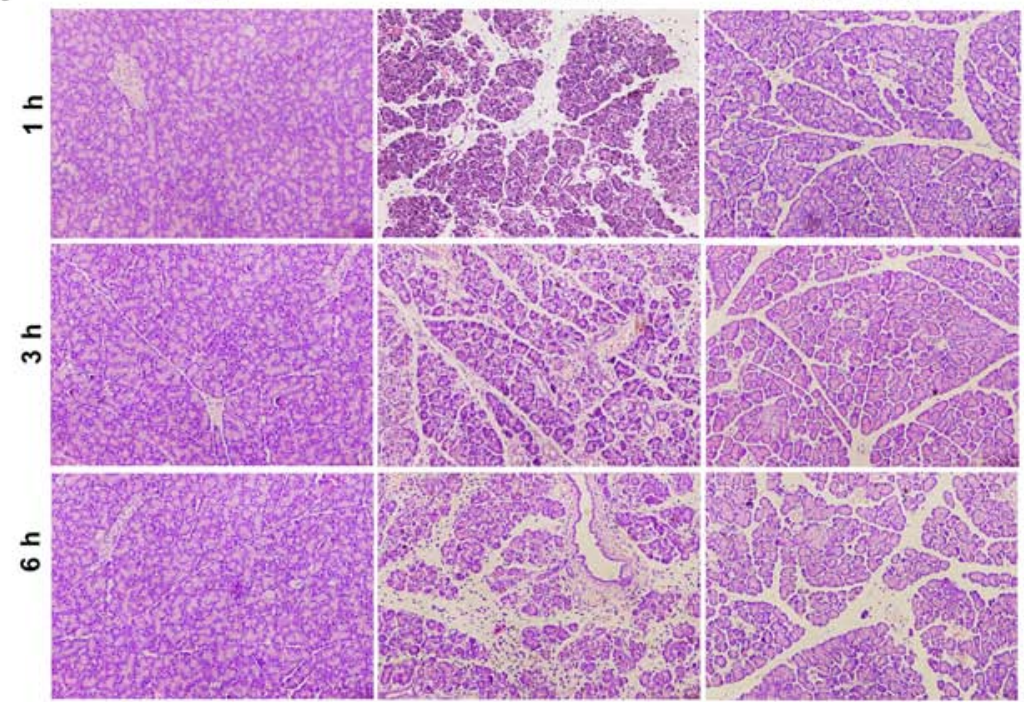

B

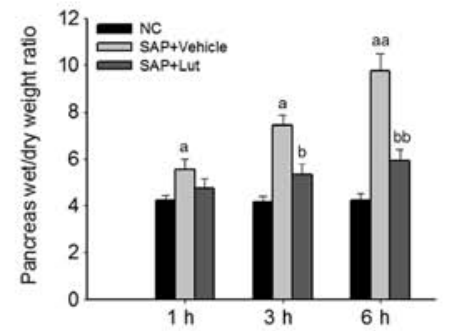

C
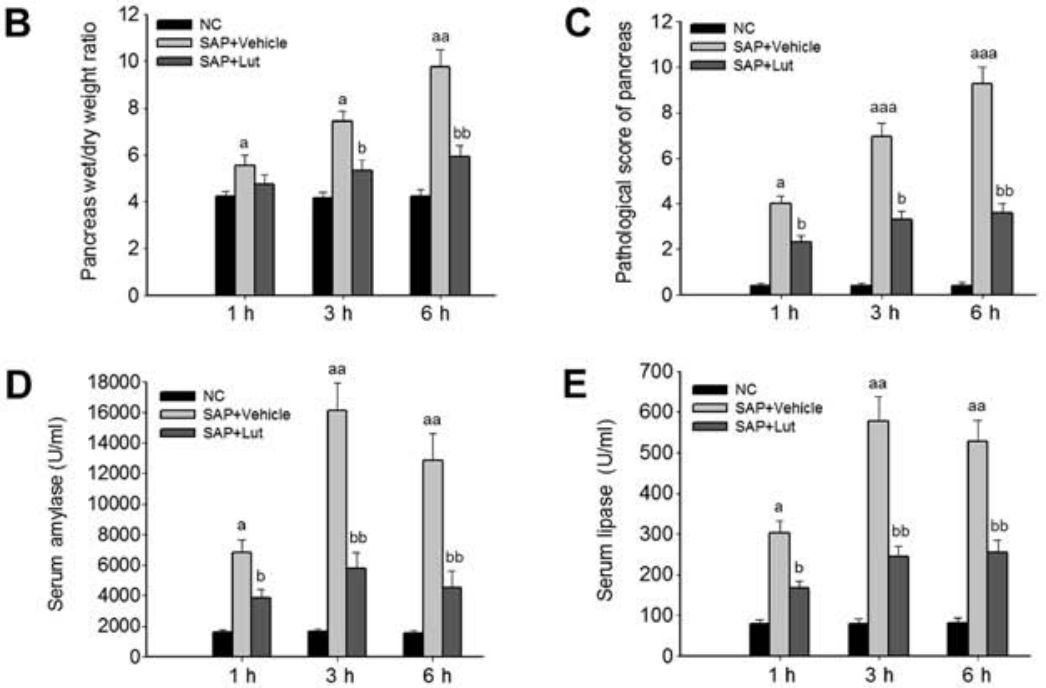

E

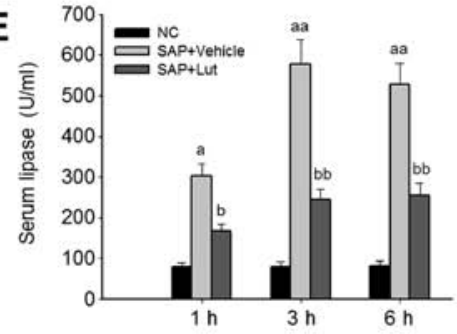

F
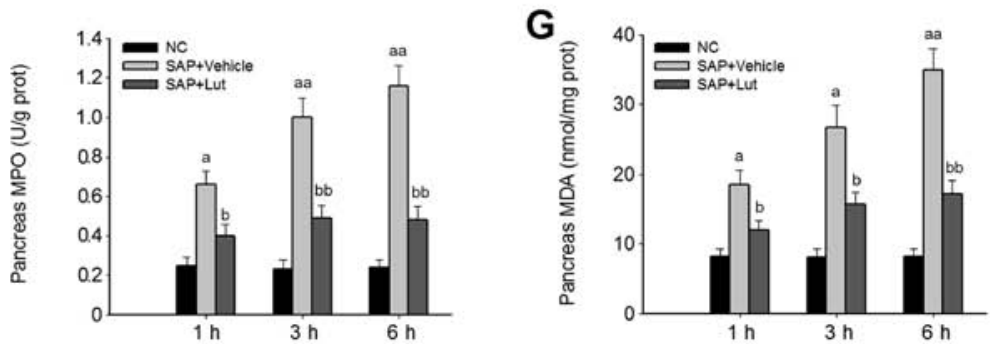

Figure 2. Luteolin (Lut) markedly improves pathological inflammatory cell infiltration in the pancreas. Mice were divided into 3 groups (n=18 per group): normal control (NC) group, severe acute pancreatitis (SAP) model group treated with the vehicle (vehicle represents SAP control group) and SAP model group treated with luteolin (Lut). Serum samples and pancreatic tissues were obtained for histological and biochemical analyses at 1,3 and $6 \mathrm{~h}$ after modeling (n=6). (A) Hematoxylin and eosin (H\&E) staining, (B) pancreas wet/dry ratios, (C) pathological scores of pancreas tissues, (D) serum amylase levels, (E) serum lipase levels, (F) myeloperoxidase (MPO) levels in pancreas, and (G) malondialdehyde (MDA) levels in pancreas. The results were similar in 3 independent experiments. Data are presented as the means \pm SEM. ${ }^{a} \mathrm{P}<0.05$ and ${ }^{a a} \mathrm{P}<0.01$ vs. $\mathrm{NC}$ group; ${ }^{\mathrm{b}} \mathrm{P}<0.05$ and ${ }^{\mathrm{b} b} \mathrm{P}<0.01$ vs. vehicle (SAP control group).

not shown). Therefore, the optimal dose of luteolin was $100 \mathrm{mg} /$ $\mathrm{kg}$, and this used in the subsequent experiments.

To investigate the potential protective role of luteolin in SAP, the wet/dry weight ratios of the pancreas and histological data of the pancreatic tissues and SAP-associated pathological markers were analyzed. The histological data revealed inflammatory acinar cell infiltration and degenerative necrosis of local acinar cells in the vehicle group at $1 \mathrm{~h}$. Patchy necrosis of acinar cells with processing lesions was observed at $3 \mathrm{~h}$. Disappearance of acinar cell structure with large necrotic areas and bleeding around the pancreas was further noted at $6 \mathrm{~h}$. However, in the Lut group, pancreatic edema and inflammatory cell infiltration were present at 3 and $6 \mathrm{~h}$, but pancreatic acinar cell necrosis was less severe (local acinar cell necrosis and unobvious bleeding around the pancreas) compared with the SAP control group (Fig. 2A). In addition, compared with the SAP control 
A

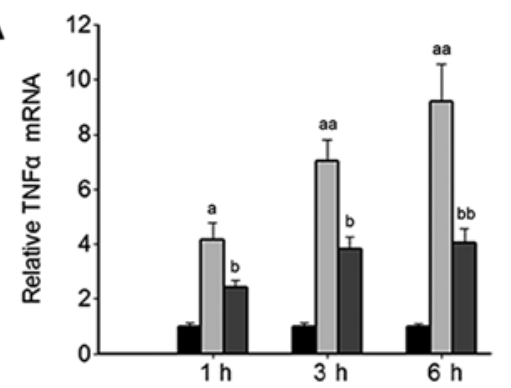

C

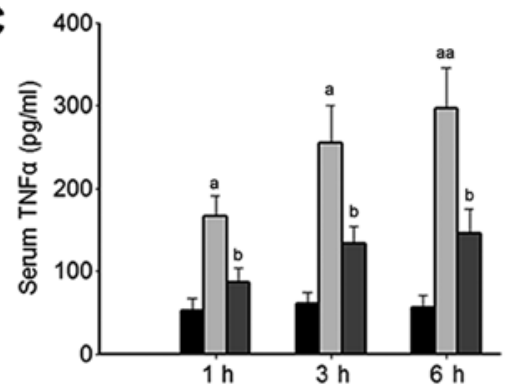

E

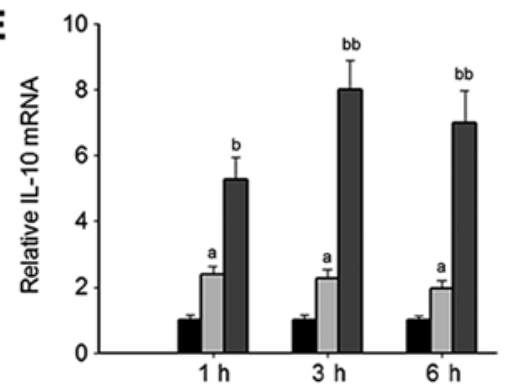

G

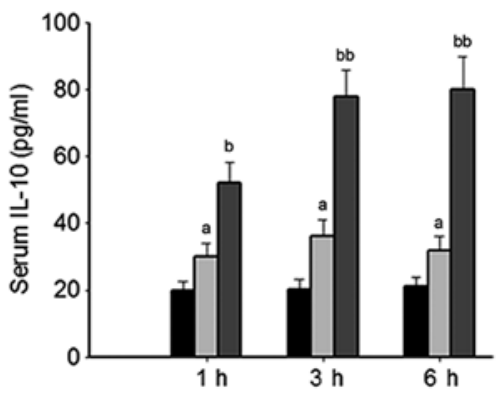

B

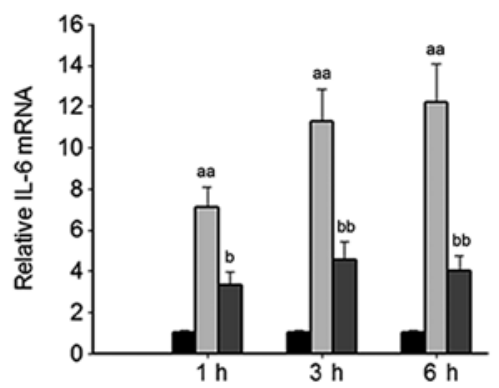

D

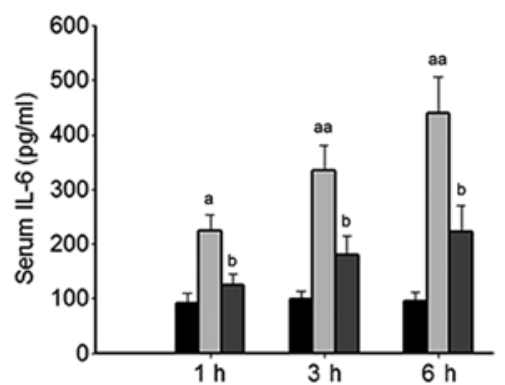

F

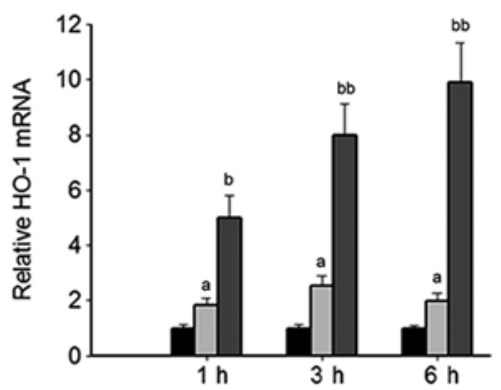

H

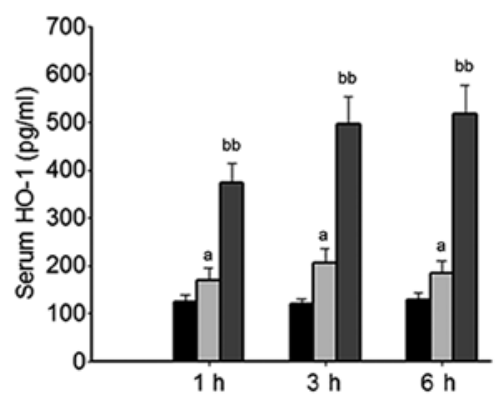

Figure 3. Luteolin (Lut) significantly decreases the levels of pro-inflammatory factors and increases heme oxygenase-1 (HO-1) and interleukin-10 (IL-10) levels in serum and pancreas specimens. (A) Tumor necrosis factor $\alpha$ (TNF $\alpha$ ) mRNA in pancreas, (B) IL-6 mRNA in pancreas, (C) serum 1 TNF $\alpha$ levels, (D) serum IL-6 levels, (E) IL-10 mRNA levels in pancreas, (F) HO-1 mRNA levels in pancreas, (G) serum IL-10 levels, and (H) serum HO-1 levels. The results were similar in 3 independent experiments. Data are presented as the means $\pm \mathrm{SEM}$. ${ }^{\mathrm{a}} \mathrm{P}<0.05$ and ${ }^{\text {aa }} \mathrm{P}<0.01 \mathrm{vs}$. NC group; ${ }^{\text {b }}<0.05$ and ${ }^{\text {b }} \mathrm{P}<0.01$ vs. vehicle $[\mathrm{severe}$ acute pancreatitis (SAP) control group].

group, treatment with luteolin significantly reduced the wet/dry weight ratios of the pancreas at 3 and $6 \mathrm{~h}$ (Fig. 2B). Accordingly, the pathological scores of the pancreas in the Lut group were significantly decreased compared with those obtained in the SAP control group at 1, 3 and $6 \mathrm{~h}$ (Fig. 2C). In agreement with the changes observed in the pancreas, the serum amylase and lipase amounts, and the MPO and MDA levels in the pancreas were significantly suppressed in the Lut group compared with the SAP control group values (Fig. 2D-G).

Treatment with luteolin significantly decreases pro-inflammatory cytokine levels and increases the amounts of HO-1 and IL-10 in serum and pancreas. Based on the above-mentioned results, the effects of luteolin on the systemic inflammatory response were further investigated. Considering that HO-1 is a potential target for the treatment of SAP $(18,19)$, the effects of luteolin on HO-1 expression were analyzed. The levels of pro-inflammatory cytokines, including TNF $\alpha$ and IL- 6 in serum and pancreatic tissue were significantly increased in the mice with SAP treated with the vehicle (SAP control group) compared with those of the normal mice (NC group), and were significantly inhibited in the mice with SAP by treatment with luteolin (Lut group, Fig. 3A-D). Furthermore, the HO-1 and IL-10 mRNA levels were significantly increased in the Lut group compared with the SAP control 

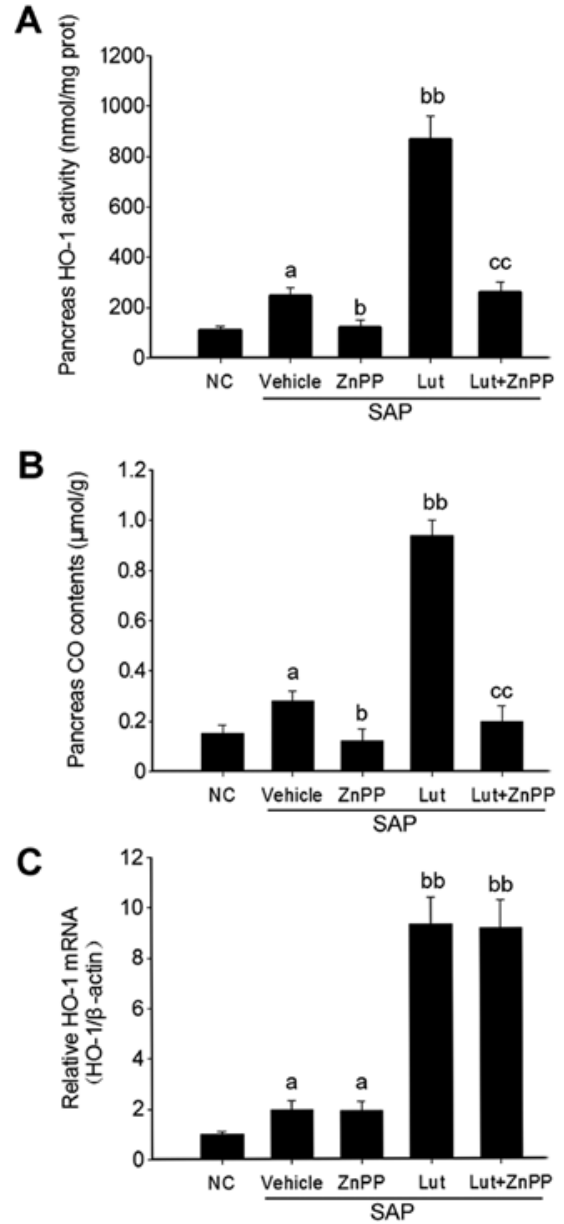

D

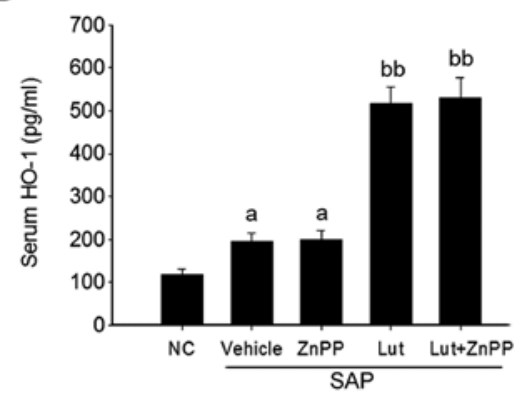

E
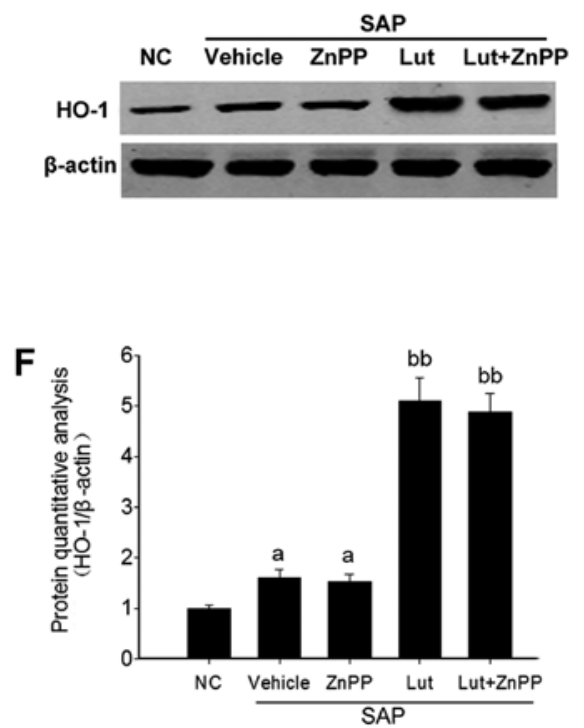

Figure 4. Zinc protoporphyrin (ZnPP) inhibits heme oxygenase-1 (HO-1) enzymatic activity, but not its expression in the pancreas. Mice were divided into 5 groups ( $\mathrm{n}=8$ per group): normal control (NC), severe acute pancreatitis (SAP) model treated with vehicle (vehicle represents SAP control group), SAP model treated with luteolin (Lut), SAP model treated with ZnPP (ZnPP) and SAP model treated with luteolin plus ZnPP (Lut + ZnPP). Serum samples and pancreas were obtained for analysis at $6 \mathrm{~h}$ after modeling. (A) HO-1 activity in the pancreas (showed by concentration of its main catalysate bilirubin), (B) carbon monoxide (CO) contents in the pancreas (another catalyst of HO-1), (C) HO-1 mRNA levels, (D) serum HO-1 levels, (E) HO-1 protein levels, and (F) quantity of HO-1 protein normalized to $\beta$-actin. The results were similar in 3 independent experiments. Data are presented as the means $\pm \mathrm{SEM}$. ${ }^{\mathrm{a}} \mathrm{P}<0.05$ vs. $\mathrm{NC}$ group; ${ }^{\mathrm{b}} \mathrm{P}<0.05$ and ${ }^{\mathrm{bb}} \mathrm{P}<0.01$ vs. vehicle (SAP control group); ${ }^{\text {cc }} \mathrm{P}<0.01$ vs. Lut group.

group (Fig. 3E and F). Consistently, the levels of HO-1 and IL-10 in serum were significantly elevated in the Lut group compared with the SAP control group (Fig. 3G and H).

ZnPP effectively suppresses the enzymatic activity, but not the expression of HO-1 in the pancreas. To determine whether the protective effects of luteolin are dependent on HO-1, ZnPP, a selective HO-1 activity competitive inhibitor $(31,32)$, was used in this study. Firstly, the inhibitory effect of ZnPP was determined. The results revealed that HO-1 activity and the level of another catalyst, $\mathrm{CO}$, were significantly inhibited in the pancreatic tissues of mice in both the $\mathrm{ZnPP}$ group and the Lut $+\mathrm{ZnPP}$ group (Fig. 4A and B). However, the mRNA and protein levels of HO-1 in the pancreas, as well as the HO-1 level in serum, were not significantly affected by $\mathrm{ZnPP}$ treatment (Fig. 4C-F).

Inhibition of HO-1 abolishes the protective effects of luteolin on cerulein plus LPS-induced SAP in mice. Based on effective inhibition of HO-1 activity by ZnPP, the protective effects of luteolin against SAP were further investigated. As shown in Fig. 5A, tissue necrosis and inflammatory infiltration were more severe in the mice in the Lut $+\mathrm{ZnPP}$ group than those in the Lut group. The wet/dry ratios and pathological scores of the pancreas were also significantly higher in the mice in the Lut + ZnPP group than those in the Lut group (Fig. 5B and C). In addition, the serum amylase and lipase levels, and pancreatic MPO amounts were almost totally reversed in the mice in the Lut + ZnPP compared with those in the Lut group (Fig. 5D-F). Although ZnPP inhibited HO-1 activity to a certain degree, which was similar to the level of HO-1 activity in the vehicle group (Fig. 4A), ZnPP almost totally abolished the effect of luteolin in terms of histological phenotype, pathological scores and biochemical indexes (Fig. 5). In addition, treatment with ZnPP only did not alter the phenotype of mice with SAP (Fig. 5).

Luteolin improves the antioxidant activity via $\mathrm{HO}-1$ in the pancreas. Given that luteolin plays a key role in the regulation of oxidative stress (18), the effects of luteolin and luteolin plus $\mathrm{ZnPP}$ on the MDA level and SOD activity were determined in order to explore the mechanisms through which luteolin improves SAP through its antioxidant activity via the induction of HO-1 expression. The MDA levels in the pancreas were significantly increased in the mice with SAP treated with the vehicle (SAP control group), and were significantly 


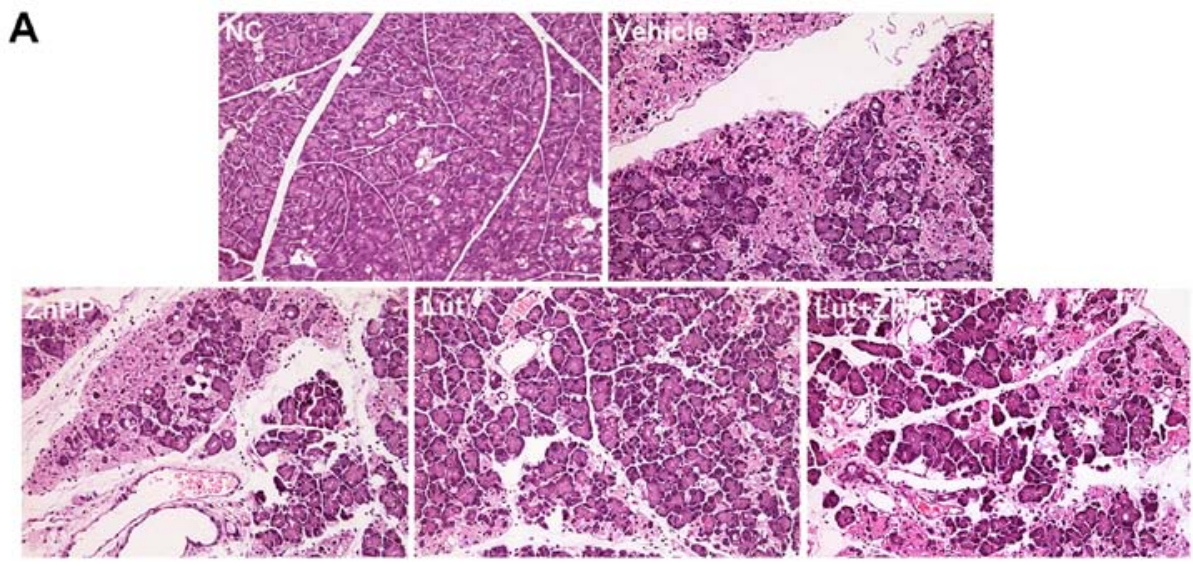

B

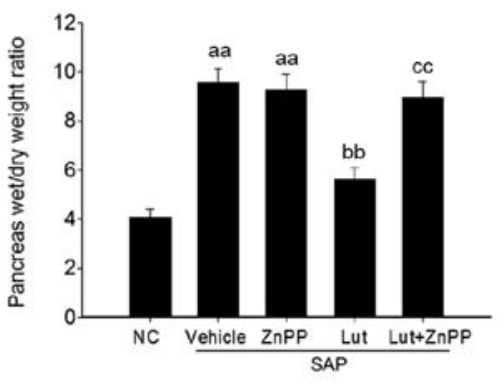

C

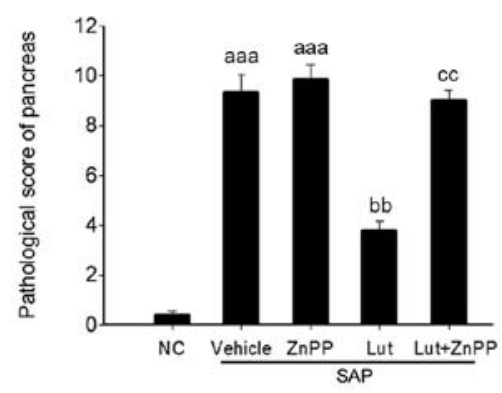

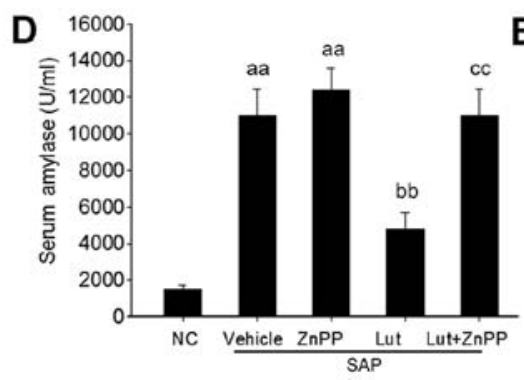
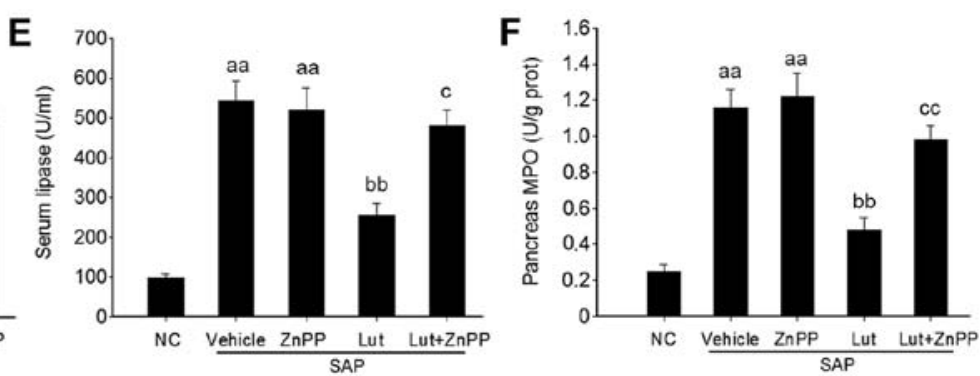

Figure 5. Heme oxygenase-1 (HO-1) inhibition by zinc protoporphyrin (ZnPP) reverses the protective effect of Luteolin (Lut). (A) Hematoxylin and eosin (H\&E) staining, (B) pancreas wet/dry ratios, (C) pathological scores of pancreatic tissue, (D) serum amylase levels, (E) serum lipase levels, and (F) pancreatic myeloperoxidase (MPO) levels. The results were similar in 3 independent experiments. Data are presented as the means \pm SEM. ${ }^{\text {aa }} \mathrm{P}<0.01$ and ${ }^{\text {aaaa }}<0.001 \mathrm{vs}$. normal control (NC) group; ${ }^{\text {bb }} \mathrm{P}<0.01$ vs. vehicle [severe acute pancreatitis (SAP) control group]; ${ }^{\mathrm{C}} \mathrm{P}<0.05$ and ${ }^{\mathrm{cc}} \mathrm{P}<0.01$ vs. Lut group.
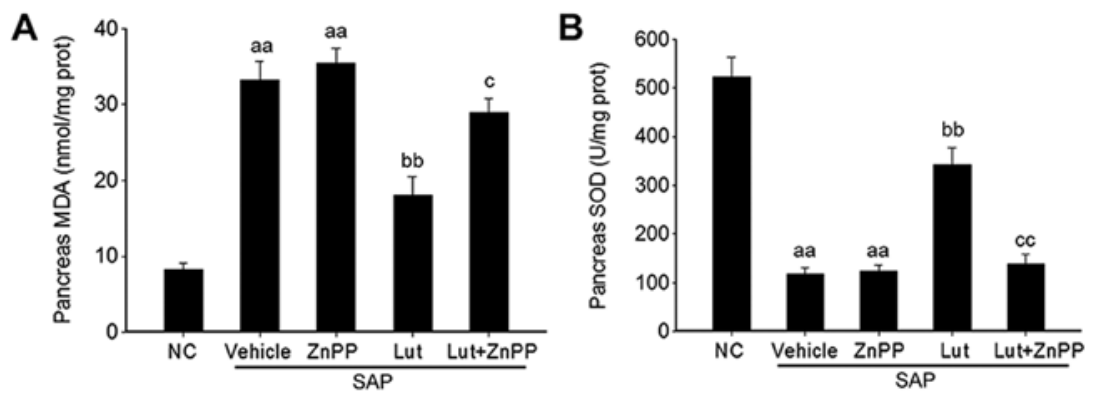

Figure 6. Luteolin (Lut) improves the antioxidant activity via heme oxygenase-1 (HO-1) in the pancreas. (A) Malondialdehyde (MDA) levels in the pancreas, and (B) superoxide dismutase (SOD) activity in the pancreas. The results were similar in 3 independent experiments. Data are presented as the means \pm SEM. ${ }^{\text {aa }} \mathrm{P}<0.01$ vs. normal control (NC) group, ${ }^{\text {bb }} \mathrm{P}<0.01$ vs. vehicle [severe acute pancreatitis (SAP) control group), ${ }^{c} \mathrm{P}<0.05$ and ${ }^{\text {cc }} \mathrm{P}<0.01$ vs. Lut group.

reduced by treatment with luteolin (Lut group); the inhibitory effects of luteolin on the MDA levels were abolished by treatment of the mice with ZnPP (Lut + ZnPP group) (Fig. 6A). Conversely, SOD activity in the pancreas was significantly decreased in the mice in the SAP control group, and was significantly stimulated by treatment with luteolin (Lut group); however, this effect was also abolished by treatment with ZnPP (Lut + ZnPP group) (Fig. 6B). In addition, treatment with ZnPP only (ZnPP group) did not affect the serum MDA levels or pancreatic SOD activity (Fig. 6A and B). 
A

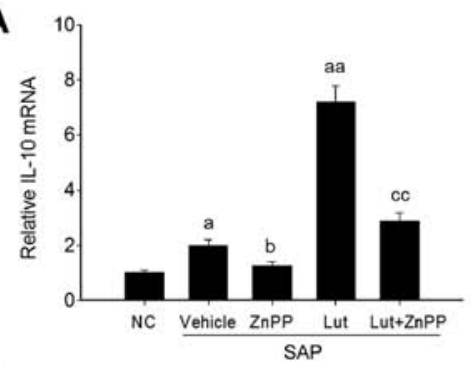

C

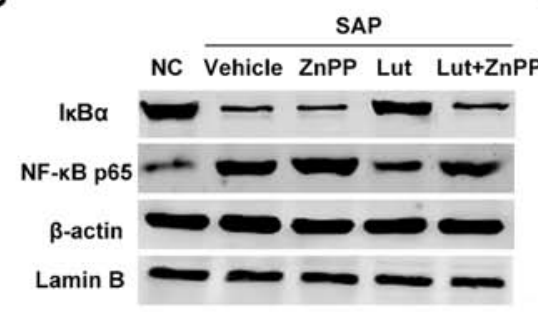

B
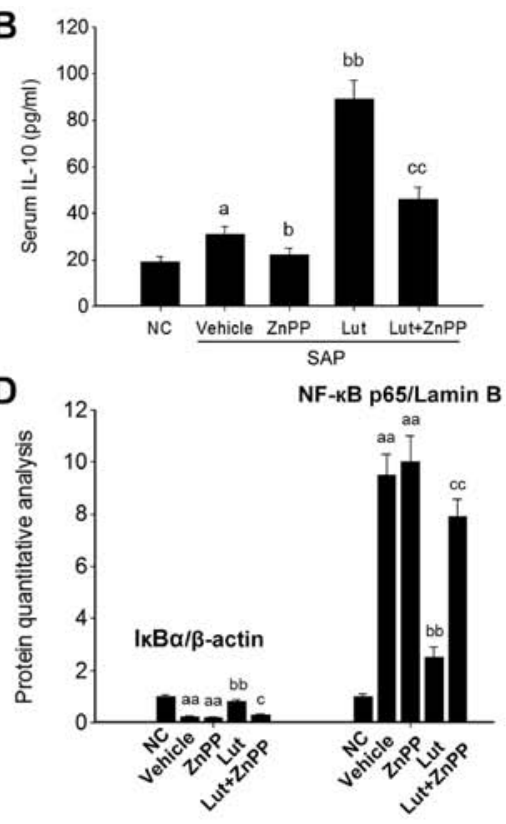

E
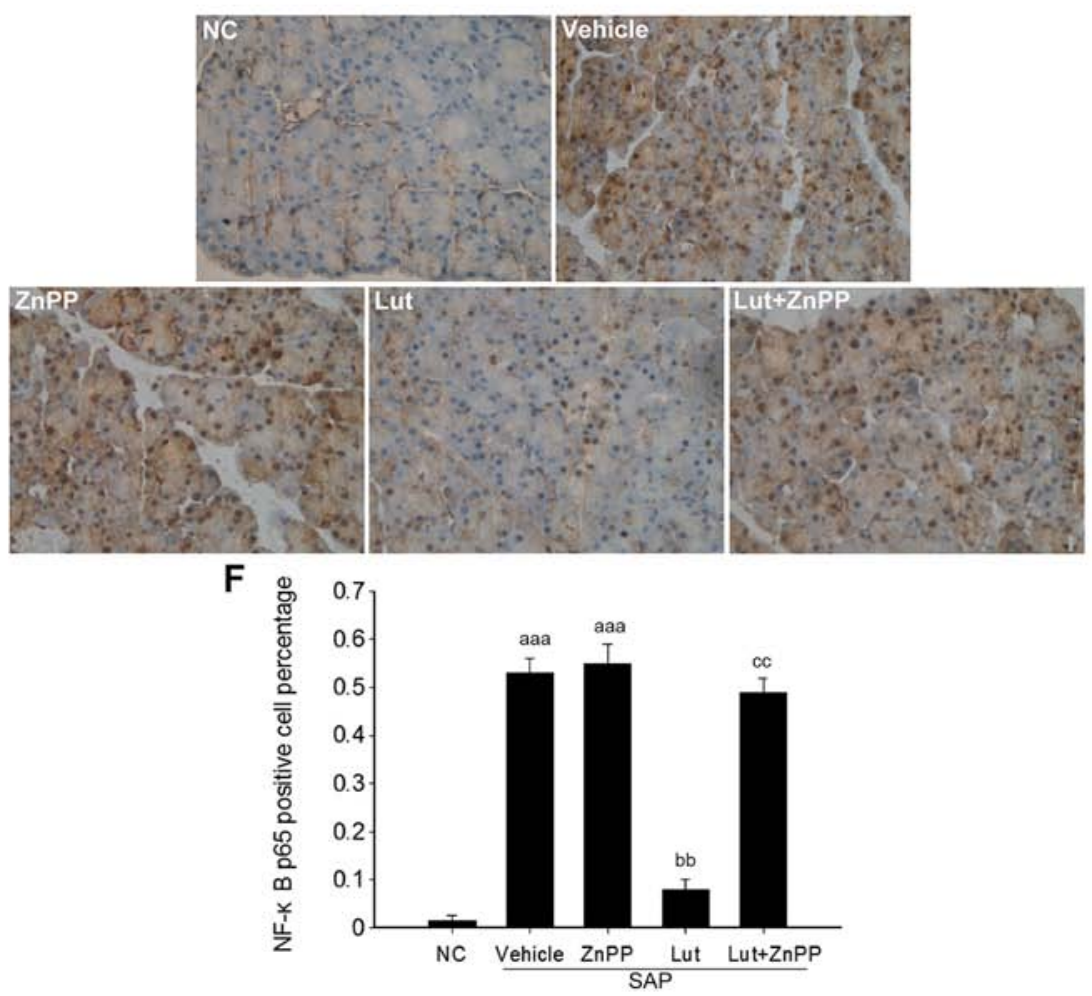

Figure 7. Luteolin (Lut) improves the anti-inflammatory activity by suppressing heme oxygenase-1 (HO-1)-mediated nuclear factor- $\kappa \mathrm{B}$ (NF- $\mathrm{kB}$ ) signaling in the pancreas. (A) Interleukin-10 (IL-10) mRNA levels in the pancreas, (B) serum IL-10 levels, (C and D) expression of NF- $\kappa B$ p65 and its inhibiting protein IкB $\alpha$

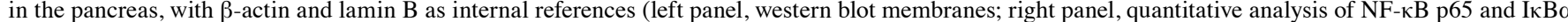
normalized to $\beta$-actin and lamin B, respectively), (E) immunohistochemical analysis of NF- $\mathrm{KB}$ in the pancreas, and (F) quantification of NF- $\mathrm{kB}$-positive cells in 5 independent immunohistochemical images. Data are presented as the means $\pm \mathrm{SEM} .{ }^{\mathrm{a}} \mathrm{P}<0.05,{ }^{\text {aa }} \mathrm{P}<0.01$ and ${ }^{\text {aaa }} \mathrm{P}<0.001$ vs. $\mathrm{NC}$ group; ${ }^{\mathrm{b}} \mathrm{P}<0.05$ and ${ }^{\mathrm{b}} \mathrm{P}<0.01$ vs. vehicle [severe acute pancreatitis (SAP) control group]; ${ }^{\mathrm{P}}<0.05$ and ${ }^{\mathrm{cc}} \mathrm{P}<0.01$ vs. Lut group.

Luteolin improves the anti-inflammatory activity via $\mathrm{HO}-1$ in the pancreas. To further investigate the involvement of HO-1 in the effects of luteolin on SAP, inflammatory markers were determined in the pancreatic tissues of mice in the Lut and Lut + ZnPP groups. The Pncreatic IL-10 mRNA levels and the serum IL-10 levels were significantly increased in the Lut group, and were significantly decreased in the Lut + ZnPP group (Fig. 7A and B). Given that HO-1 plays a role in regulating NF- $\mathrm{BB}$ signaling, the expression levels of two key proteins of the NF- $\mathrm{KB}$ signaling pathway, including

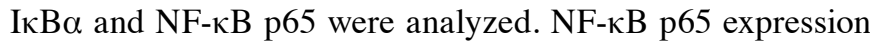
was significantly increased in the pancreatic tissues of mice with SAP, and was significantly suppressed by treatment with luteolin. Conversely, the expression of I $\mathrm{K} \mathrm{B} \alpha$, an inhibitory protein of NF- $\mathrm{kB}$ p65, was significantly inhibited in the pancreatic tissues of mice with SAP, and was significantly 


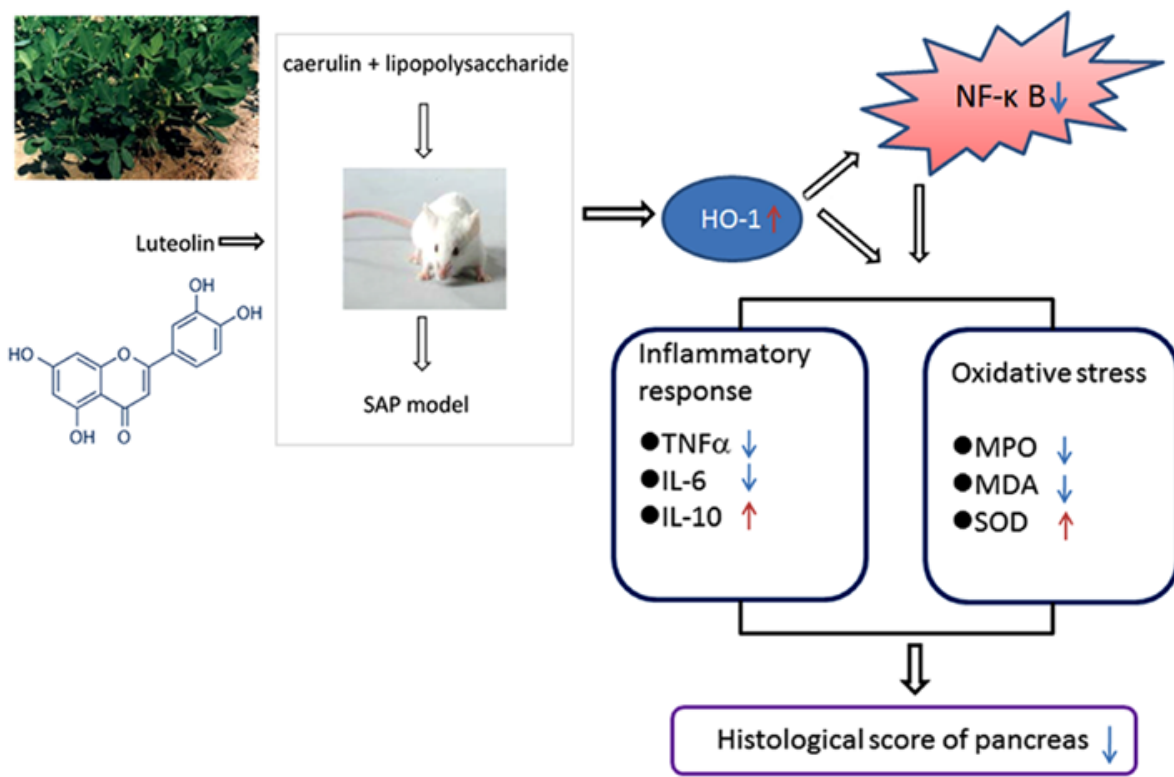

Figure 8. Schematic model of possible underlying mechanism of luteolin (Lut) improving cerulein plus lipopolysaccharide (LPS)-induced severe acute pancreatitis (SAP) in mice via induction of heme oxygenase-1 (HO-1)-mediated anti-inflammatory and antioxidant activities, associated with nuclear factor- $\kappa \mathrm{B}$ (NF- $\mathrm{kB}$ ) pathway suppression.

stimulated by treatment with luteolin (Fig. 7C and D). The activation of NF- $\mathrm{KB}$ is associated with its translocation from the cytoplasm to the nucleus. Immunohistochemical analysis indicated that the NF- $\mathrm{KB}$ p 65 levels in the nucleus were markedly increased in the pancreatic tissues of mice with SAP, and was significantly decreased in the Lut group (Fig. 7E), which suggested that luteolin effectively suppressed the activation of $\mathrm{NF}-\mathrm{kB}$ in the pancreas of mice with SAP. In addition, treatment with ZnPP only did not affect the pancreatic IL-10 mRNA level and serum IL-10 amounts, as well as the expression of IкB $\alpha$ and NF-кB p65 (Fig. 7).

\section{Discussion}

During the SAP inflammatory response, common signal transduction pathways are induced by pro-inflammatory cytokines and oxidative stress, and are activated by the mitogen-activated protein kinase (MAPK) and NF- $\mathrm{kB}$ signaling pathways, resulting in inflammatory cascade amplification (33). The improvement of oxidative stress and the inflammatory response is the main mechanism of alleviating SAP. In this study, luteolin protected mice from cerulein plus LPS-induced SAP, via the HO-1 regulation of oxidative stress and the inflammatory process.

In this study, the continuous administration of cerulein combined with LPS was used to induce SAP, which shares the pathological changes observed clinically in SAP; the model is therefore widely used in mouse studies of SAP $(25,34)$. In the present study, cerulein combined with LPS effectively induced SAP in mice, which displayed higher pathological scores in the pancreas, increased levels of TNF $\alpha$ and IL-6, and enhanced NF- $\mathrm{kB}$ activity in the pancreas, suggesting that the cerulein plus LPS-induced SAP model is an effective tool for studying the mechanisms of action and treatment effects in SAP.

Luteolin has been wildly used as a traditional Asian medicine for the treatment of diseases associated with oxidative injury and acute inflammation, such as endotoxemia, acute lung injury, acute myocardial infarction and hepatitis (4-6). However, the pharmacological toxicity of luteolin has not been studied in detail. In this study, we firstly assessed the pharmacological toxicity of luteolin. The results revealed that the $\mathrm{LD}_{50}$ for luteolin was $460 \mathrm{mg} / \mathrm{kg}$. Of note, $100 \mathrm{mg} / \mathrm{kg}$ luteolin displayed no liver or kidney toxicity, suggesting a good safety profile for luteolin (data not shown).

Luteolin has many known properties: anti-inflammatory, antioxidant and anti-fibrotic effects $(4,6,35)$. The oral administration of luteolin $(10 \mathrm{mg} / \mathrm{kg})$ has been shown to effectively suppress neutrophil infiltration, as well as the increase in TNF $\alpha$ and IL-6 levels in bronchoalveolar lavage fluid from bleomycin-instilled C57BL/6J mice (36). Luteolin injected intraperitoneally at different doses of 10 or $25 \mathrm{mg} / \mathrm{kg}$ has also beehn shown to significantly increase SOD1 activity and decrease MDA levels in mice with permanent middle cerebral artery occlusion, which results in alleviated neurological deficits, infarct volume and brain water content (37). In the present study, luteolin significantly alleviated SAP in mice at $100 \mathrm{mg} / \mathrm{kg}$. With regards to its anti-inflammatory activity, luteolin significantly suppressed the cerulein plus LPS-induced increase in TNF $\alpha$ and IL-6 levels in the pancreas and serum, and the IL-10 levels were significantly increased by treatment with luteolin. Furthermore, luteolin significantly suppressed the cerulein plus LPS-induced increase in MDA levels, and stimulated SOD1 activity in the pancreas. Taken together, these results suggest that luteolin is a protective agent for SAP, and HO-1 is a potential drug target for the treatment of SAP. Given that a higher dose $(100 \mathrm{mg} / \mathrm{kg})$ of luteolin was used in this study compared with previous studies (10 or $25 \mathrm{mg} / \mathrm{kg}$ ) (38), lower doses of luteolin and their effects on SAP warrant further investigation.

During the occurrence of SAP, high oxygen free radicals (OFRs) cause biomembrane lipid peroxidation, generating MDA; proteins are further peroxidized, causing DNA damage 
and resulting in apoptosis (39-41). OFR can also activate $\mathrm{NF}-\kappa \mathrm{B}$, enhancing TNF $\alpha$ and IL-6 levels. Furthermore, proinflammatory cytokines combined with OFR trigger common signaling pathways mainly by $\mathrm{NF}-\kappa \mathrm{B}$ activation, further causing inflammatory cascade reactions (42-44). In this study, the MDA levels in the model group increased at $6 \mathrm{~h}$ compared with the NC group, suggesting an overt oxidative stress in SAP. Luteolin significantly decreased the MDA levels; however, this effect was suppressed when luteolin was administered in combination with ZnPP. This indicated that the antioxidant properties of luteolin depended, at least in part, on HO-1. On the other hand, SOD is an important OFR scavenger (45). Not only has HO-1 been described as an antioxidant, it also induces the expression of other antioxidants, such as SOD and catalase to fight oxidative stress $(46,47)$. In this study, SOD activity in the pancreatic tissue at $6 \mathrm{~h}$ in the model group was significantly reduced compared with the NC group value. Luteolin overtly increased SOD activity, which was reduced following combined treatment with ZnPP, a HO-1 activity inhibitor. This suggested that luteolin induces SOD expression by upregulating HO-1 expression, playing an antioxidant role. Previous studies have indicated that panhematin leads to the rapid induction and activation of pancreatic HO-1, and hemin-like compounds or hemin-activated macrophages upregulate $\mathrm{HO}-1$ expression in the pancreas to prevent AP via the upregulation of HO-1 $(16,17)$. These findings indicated that $\mathrm{HO}-1$ is a potential target for the treatment of SAP.

It is widely known that over-activated inflammatory cells and factors are closely related to the damage caused by SAP, and inflammatory factors are regulated by $\mathrm{NF}-\kappa \mathrm{B}$ at the gene level (48). NF- $\kappa \mathrm{B}$ is widely distributed in multiple cell types, and is mainly composed of p50 and p65 subunits in the form of homo- or hetero-dimers. In SAP, a high expression of $\mathrm{NF}-\kappa \mathrm{B}$ enhances pro-inflammatory cytokines, such as TNF $\alpha$ and IL-6 to release. Moreover, TNF $\alpha$ and IL-6 increase NF- $\kappa$ B activity by positive feedback, further enhancing the transcription of related cytokines, which enhances the severity of the condition. It has been demonstrated that limiting NF- $\mathrm{KB}$ activation significantly reduces the severity of SAP (49). Antioxidants can inhibit $\mathrm{NF}-\kappa \mathrm{B}$ activation effectively, including n-acetyl-cysteine, pyrrolidine dithiocarbamate (PDTC) and ethyl acetonate, which have certain therapeutic effects. However, NF- $\kappa$ B inhibitors with non-specific effects will suppress other signaling pathways and have potential toxicity, which limit their applications (50). As shown in this study, luteolin significantly inhibited $\mathrm{NF}-\kappa \mathrm{B}$ p65 expression and stimulated $\mathrm{I} \kappa \mathrm{B} \alpha$ expression. The suppression of HO-1 activity using ZnPP abolished the effects of luteolin NF- $\kappa \mathrm{B}$ p 65 and $\mathrm{I} \kappa \mathrm{B} \alpha$ expression. Therefore, luteolin inhibits $\mathrm{NF}-\kappa \mathrm{B}$ activity to exert anti-inflammatory effects in a HO-1-dependent manner.

HO-1 and its catalysts involved in maintaining cellular homeostasis play important protective roles by counteracting oxidative damage, the inflammatory response and cell apoptosis, and also regulate cell proliferation. It was recently demonstrated that $\mathrm{CO}$ is also an endothelium-derived relaxing factor involved in the regulation of several physiological and pathological processes, with many effects, such as relaxing the vascular smooth muscle, inhibiting platelet aggregation and neutrophil adhesion, and regulating nerve, body fluid and endocrine functions $(51,52)$. $\mathrm{CO}$ at low concentrations selectively inhibits the expression of pro inflammatory cytokines and increases IL-10 levels through MAPK, which is activated by mitogen $(53,54)$. IL-10 is an important anti-inflammatory cytokine generated by Th2-lymphocytes; it can inhibit TNF $\alpha$ and IL-6 synthesis, and can protect against multiple organ damage caused by SAP. In the early stages of SAP, IL-10 levels are slightly increased. However, this increase is much less than that of pro-inflammatory cytokines, which enhances the severity of the patient's condition. Therefore, finding an adequate balance between pro- and anti-inflammatory cytokines in the treatment of SAP may be a useful solution. In this study, IL-10 expression in the SAP group was slightly higher than that in the NC group as detected by ELISA, in line with previous studies $(55,56)$. Of note, luteolin significantly increased the level of IL-10, which depends on HO-1 activity. These results suggested that luteolin plays its protective role in SAP by inducing IL-10 in a HO-1dependent manner.

Accumulating evidence indicates that nuclear factor (erythroid-derived 2)-like 2 (Nrf2) signaling is involved in the protective effects of luteolin against oxidative stress (32,57-60). Furthermore, Nrf2, as the guardian of redox homeostasis, activates a battery of antioxidant and cytoprotective genes that share in common a cis-acting enhancer sequence termed antioxidant response element (ARE) that include HO-1 in response to oxidative stress (61). Thus, we hypothesized that luteolin induces HO-1 expression in an Nrf2-dependent manner, and we aim to investigate this hypothesis in future studies.

In conclusion, our data demonstrated that luteolin significantly improved cerulein plus LPS-induced SAP in mice. These effects depended on HO-1 induction by luteolin: increased HO-1 levels decreased NF- $\kappa$ B activity, increased anti-inflammatory and antioxidant activities, reduced lipid peroxidation, and increased IL-10 levels (Fig. 8). These findings suggest that luteolin is a potential protective agent for SAP.

\section{Acknowledgements}

This study was supported by the National Natural Science Foundation of China (grant nos. 81570580 and 81270928) and Doctoral Innovation Fund of Shanghai Jiao Tong University School of Medcine (grant no. BXJ201440).

\section{References}

1. Di Fabio F, Abu Hilal M and Johnson CD: Acute pancreatitis: mild, severe or potentially fatal. Pancreatology 11: 373-375, 2011.

2. Rebours V: Acute pancreatitis: an overview of the management. Rev Med Interne 35: 649-655, 2014 (In French).

3. Talukdar R and Vege SS: Acute pancreatitis. Curr Opin Gastroenterol 31: 374-379, 2015.

4. Seelinger G, Merfort I and Schempp CM: Anti-oxidant, anti-inflammatory and anti-allergic activities of luteolin. Planta Med 74: 1667-1677, 2008.

5. Kuo MY, Liao MF, Chen FL, Li YC, Yang ML, Lin RH and Kuan YH: Luteolin attenuates the pulmonary inflammatory response involves abilities of antioxidation and inhibition of MAPK and NFKB pathways in mice with endotoxin-induced acute lung injury. Food Chem Toxicol 49: 2660-2666, 2011.

6. Nabavi SF, Braidy N, Gortzi O, Sobarzo-Sanchez E, Daglia M, Skalicka-Woźniak K and Nabavi SM: Luteolin as an anti-inflammatory and neuroprotective agent: a brief review. Brain Res Bull 119: 1-11, 2015.

7. Sung $\mathrm{J}$ and Lee J: Anti-Inflammatory activity of butein and luteolin through suppression of $\mathrm{NF \kappa B}$ activation and induction of heme oxygenase-1. J Med Food 18: 557-564, 2015. 
8. Maines MD: The heme oxygenase system: a regulator of second messenger gases. Annu Rev Pharmacol Toxicol 37: 517-554, 1997.

9. Yu M, Wang J, Fang Q, Liu P, Chen S, Zhe N, Lin X, Zhang Y, Zhao $J$ and Zhou Z: High expression of heme oxygenase-1 in target organs may attenuate acute graft-versus-host disease through regulation of immune balance of TH17/Treg. Transpl Immunol 37: 10-17, 2016.

10. Wu B, Song HL, Yang Y, Yin ML, Zhang BY, Cao Y, Dong C and Shen ZY: Improvement of liver transplantation outcome by heme oxygenase-1-transduced bone marrow mesenchymal stem cells in rats. Stem Cells Int 2016: 9235073, 2016.

11. Nath KA: Heme oxygenase-1 and acute kidney injury. Curr Opin Nephrol Hypertens 23: 17-24, 2014.

12. Lever JM, Boddu R, George JF and Agarwal A: Heme oxygenase-1 in kidney health and disease. Antioxid Redox Signal 25: $165-183,2016$

13. Durante W: Targeting heme oxygenase-1 in vascular disease. Curr Drug Targets 11: 1504-1516, 2010.

14. Wu ML, Ho YC and Yet SF: A central role of heme oxygenase-1 in cardiovascular protection. Antioxid Redox Signal 15: 1835-1846, 2011.

15. Chang M, Xue J, Sharma V and Habtezion A: Protective role of hemeoxygenase-1 in gastrointestinal diseases. Cell Mol Life Sci 72: 1161-1173, 2015

16. Habtezion A, Kwan R, Akhtar E, Wanaski SP, Collins SD Wong RJ, Stevenson DK, Butcher EC and Omary MB: Panhematin provides a therapeutic benefit in experimental pancreatitis Gut 60: 671-679, 2011.

17. Nakamichi I, Habtezion A, Zhong B, Contag CH, Butcher EC and Omary MB: Hemin-activated macrophages home to the pancreas and protect from acute pancreatitis via heme oxygenase-1 induction. J Clin Invest 115: 3007-3014, 2005.

18. Nuhn P, Mitkus T, Ceyhan GO, Künzli BM, Bergmann F, Fischer L, Giese N, Friess H and Berberat PO: Heme oxygenase 1generated carbon monoxide and biliverdin attenuate the course of experimental necrotizing pancreatitis. Pancreas 42: 265-271, 2013.

19. Habtezion A, Kwan R, Yang AL, Morgan ME, Akhtar E, Wanaski SP, Collins SD, Butcher EC, Kamal A and Omary MB: Heme oxygenase- 1 is induced in peripheral blood mononuclear cells of patients with acute pancreatitis: a potential therapeutic target. Am J Physiol Gastrointest Liver Physiol 300: G12-G20, 2011.

20. Bellezza I, Tucci A, Galli F, Grottelli S, Mierla AL, Pilolli F and Minelli $A$ : Inhibition of NF- $\mathrm{B}$ nuclear translocation via HO-1 activation underlies $\alpha$-tocopheryl succinate toxicity. J Nutr Biochem 23: 1583-1591, 2012.

21. Yeh CH, Chen TP, Wang YC, Lin YM and Lin PJ: HO-1 activation can attenuate cardiomyocytic apoptosis via inhibition of NF-kappaB and AP-1 translocation following cardiac global ischemia and reperfusion. J Surg Res 155: 147-156, 2009.

22. López Martín A and Carrillo Alcaraz A: Oxidative stress and acute pancreatitis. Rev Esp Enferm Dig 103: 559-562, 2011.

23. Rakonczay Z Jr, Hegyi P, Takács T, McCarroll J and Saluja AK: The role of NF-kappaB activation in the pathogenesis of acute pancreatitis. Gut 57: 259-267, 2008.

24. Peng Y, Gallagher SF, Landmann R, Haines K and Murr MM: The role of p65 NF-kappaB/RelA in pancreatitis-induced Kupffer cell apoptosis. J Gastrointest Surg 10: 837-847, 2006.

25. Norkina O, Graf R, Appenzeller P and De Lisle RC: Caerulein-induced acute pancreatitis in mice that constitutively overexpress Reg/PAP genes. BMC Gastroenterol 6: 16, 2006.

26. Niederau C, Ferrell LD and Grendell JH: Caerulein-induced acute necrotizing pancreatitis in mice: protective effects of proglumide, benzotript, and secretin. Gastroenterology 88: 1192-1204, 1985

27. Song HJ, Shin CY, Oh TY and Sohn UD: The protective effect of eupatilin on indomethacin-induced cell damage in cultured feline ileal smooth muscle cells: involvement of HO-1 and ERK. J Ethnopharmacol 118: 94-101, 2008.

28. Song HJ, Shin CY, Oh TY, Min YS, Park ES and Sohn UD: Eupatilin with heme oxygenase-1-inducing ability protects cultured feline esophageal epithelial cells from cell damage caused by indomethacin. Biol Pharm Bull 32: 589-596, 2009.

29. Rongione AJ, Kusske AM, Kwan K, Ashley SW, Reber HA and McFadden DW: Interleukin 10 reduces the severity of acute pancreatitis in rats. Gastroenterology 112: 960-967, 1997.
30. Van Laere SJ, Van der Auwera I, Van den Eynden GG, Elst HJ, Weyler J, Harris AL, van Dam P, Van Marck EA, Vermeulen PB and Dirix LY: Nuclear factor-kappaB signature of inflammatory breast cancer by cDNA microarray validated by quantitative real-time reverse transcription-PCR, immunohistochemistry, and nuclear factor-kappaB DNA-binding. Clin Cancer Res 12: 3249-3256, 2006

31. Fujioka K, Kalish F, Wong RJ and Stevenson DK: Inhibition of heme oxygenase activity using a microparticle formulation of zinc protoporphyrin in an acute hemolytic newborn mouse model. Pediatr Res 79: 251-257, 2016.

32. Sun GB, Sun X, Wang M, Ye JX, Si JY, Xu HB, Meng XB, Qin M, Sun J, Wang HW, et al: Oxidative stress suppression by luteolin-induced heme oxygenase-1 expression. Toxicol Appl Pharmacol 265: 229-240, 2012.

33. Liu HS, Pan CE, Liu QG, Yang W and Liu XM: Effect of NF-kappaB and p38 MAPK in activated monocytes/macrophages on pro-inflammatory cytokines of rats with acute pancreatitis. World J Gastroenterol 9: 2513-2518, 2003.

34. Wang X, Wang B and Wu J: Pancreatitis-associated protein-I mRNA expression in mouse pancreas is upregulated by lipopolysaccharide independent of cerulein-pancreatitis. J Gastroenterol Hepatol 16: 79-86, 2001.

35. Domitrović R, Jakovac H, Tomac J and Sain I: Liver fibrosis in mice induced by carbon tetrachloride and its reversion by luteolin. Toxicol Appl Pharmacol 241: 311-321, 2009.

36. Chen CY, Peng WH, Wu LC, Wu CC and Hsu SL: Luteolin ameliorates experimental lung fibrosis both in vivo and in vitro: implications for therapy of lung fibrosis. J Agric Food Chem 58: $11653-11661,2010$

37. Qiao H, Dong L, Zhang X, Zhu C, Zhang X, Wang L, Liu Z, Chen L, Xing Y, Wang C and Li Y: Protective effect of luteolin in experimental ischemic stroke: upregulated SOD1, CAT, Bcl-2 and claudin-5, down-regulated MDA and Bax expression. Neurochem Res 37: 2014-2024, 2012.

38. Qiao H, Zhang X, Zhu C, Dong L, Wang L, Zhang X, Xing Y, Wang C, Ji Y and Cao X: Luteolin downregulates TLR4, TLR5, NF- $\kappa \mathrm{B}$ and p-p38MAPK expression, upregulates the p-ERK expression, and protects rat brains against focal ischemia. Brain Res 1448: 71-81, 2012.

39. Ramudo L and Manso MA: N-acetylcysteine in acute pancreatitis. World J Gastrointest Pharmacol Ther 1: 21-26, 2010.

40. Modzelewski B, Janiak A and Hollynski J: Hyperlipoproteinemia in necrotizing pancreatitis. Pol Merkur Lekarski 18: 415-417, 2005 (In Polish).

41. Booth DM, Mukherjee R, Sutton R and Criddle DN: Calcium and reactive oxygen species in acute pancreatitis: friend or foe? Antioxid Redox Signal 15: 2683-2698, 2011.

42. Hackert T and Werner J: Antioxidant therapy in acute pancreatitis: experimental and clinical evidence. Antioxid Redox Signal 15: 2767-2777, 2011.

43. Kim H: Inhibitory mechanism of lycopene on cytokine expression in experimental pancreatitis. Ann N Y Acad Sci 1229: 99-102, 2011

44. Ramudo L, De Dios I, Yubero S, Vicente S and Manso MA: ICAM-1 and CD11b/CD18 expression during acute pancreatitis induced by bile-pancreatic duct obstruction: effect of N-acetylcysteine. Exp Biol Med (Maywood) 232: 737-743, 2007.

45. Li YY, Li XL, Yang CX, Zhong H, Yao H and Zhu L: Effects of tetrandrine and QYT on ICAM-1 and SOD gene expression in pancreas and liver of rats with acute pancreatitis. World J Gastroenterol 9: 155-159, 2003.

46. Fan J, Xu G, Jiang T and Qin Y: Pharmacologic induction of heme oxygenase- 1 plays a protective role in diabetic retinopathy in rats. Invest Ophthalmol Vis Sci 53: 6541-6556, 2012.

47. Turkseven S, Kruger A, Mingone CJ, Kaminski P, Inaba M, Rodella LF, Ikehara S, Wolin MS and Abraham NG: Antioxidant mechanism of heme oxygenase-1 involves an increase in superoxide dismutase and catalase in experimental diabetes. Am J Physiol Heart Circ Physiol 289: H701-H707, 2005.

48. Kim H, Seo JY and Kim KH: NF-kappaB and cytokines in pancreatic acinar cells. J Korean Med Sci 15 (Suppl): S53-S54, 2000.

49. Jin S, Orabi AI, Le T, Javed TA, Sah S, Eisses JF, Bottino R, Molkentin JD and Husain SZ: Exposure to radiocontrast agents induces pancreatic inflammation by activation of nuclear factor- $\mathrm{\kappa} \mathrm{B}$, calcium signaling, and calcineurin. Gastroenterology 149: 753-764, 2015.

50. Yang X, Jin H, Liu K, Gu Q and Xu X: A novel peptide derived from human pancreatitis-associated protein inhibits inflammation in vivo and in vitro and blocks NF-kappa B signaling pathway. PLoS One 6: e29155, 2011. 
51. Constantin M, Choi AJ, Cloonan SM and Ryter SW: Therapeutic potential of heme oxygenase-1/carbon monoxide in lung disease. Int J Hypertens 2012: 859235, 2012.

52. Barbagallo I, Marrazzo G, Frigiola A, Zappala A and Li Volti G: Role of carbon monoxide in vascular diseases. Curr Pharm Biotechnol 13: 787-796, 2012.

53. MacGarvey NC, Suliman HB, Bartz RR, Fu P, Withers CM, Welty-Wolf KE and Piantadosi CA: Activation of mitochondrial biogenesis by heme oxygenase-1-mediated NF-E2-related factor-2 induction rescues mice from lethal Staphylococcus aureus sepsis. Am J Respir Crit Care Med 185: 851-861, 2012.

54. Drechsler Y, Dolganiuc A, Norkina O, Romics L, Li W, Kodys K, Bach FH, Mandrekar P and Szabo G: Heme oxygenase-1 mediates the anti-inflammatory effects of acute alcohol on IL-10 induction involving p38 MAPK activation in monocytes. J Immunol 177: 2592-2600, 2006.

55. Vasseur P, Devaure I, Sellier J, Delwail A, Chagneau-Derrode C, Charier F, Tougeron D, Tasu JP, Rabeony H, Lecron JC and Silvain C: High plasma levels of the pro-inflammatory cytokine IL-22 and the anti-inflammatory cytokines IL-10 and IL-1ra in acute pancreatitis. Pancreatology 14: 465-469, 2014.

56. Zhang F, Fei J, Zhao B, Chen E and Mao E: Protective effect of adenoviral transfer of heme oxygenase-1 gene on rats with severe acute pancreatitis. Am J Med Sci 348: 224-231, 2014.
57. Pandurangan AK,KumarSA, Dharmalingam $P$ and Ganapasam $S$ : Luteolin, a bioflavonoid inhibits azoxymethane-induced colon carcinogenesis: involvement of iNOS and COX-2. Pharmacogn Mag 10 (Suppl 2): S306-S310, 2014.

58. Pandurangan AK, Dharmalingam P, Sadagopan SK and Ganapasam S: Luteolin inhibits matrix metalloproteinase 9 and 2 in azoxymethane-induced colon carcinogenesis. Hum Exp Toxicol 33: 1176-1185, 2014

59. Pandurangan AK, Ananda Sadagopan SK, Dharmalingam $P$ and Ganapasam S: Luteolin, a bioflavonoid inhibits azoxymethane-induced colorectal cancer through activation of Nrf2 signaling. Toxicol Mech Methods 24: 13-20, 2014.

60. Huang CS, Lii CK, Lin AH, Yeh YW, Yao HT, Li CC, Wang TS and Chen HW: Protection by chrysin, apigenin, and luteolin against oxidative stress is mediated by the Nrf2-dependent up-regulation of heme oxygenase 1 and glutamate cysteine ligase in rat primary hepatocytes. Arch Toxicol 87: 167-178, 2013.

61. Innamorato NG, Rojo AI, García-Yagüe AJ, Yamamoto M, de Ceballos ML and Cuadrado A: The transcription factor Nrf2 is a therapeutic target against brain inflammation. J Immunol 181: 680-689, 2008. 